\title{
An analysis of Crohn's disease activity indices from a registry of patients in eastern Pennsylvania
}

\author{
JF REED III, PHD, LINDA A FAUST, BS
}

JF REED III, LA FAUST. An analysis of Crohn's disease activity indices from a registry of patients in eastern Pennsylvania. Can J Gastroenterol 1991;5(6): 199-208. The objectives of this report were to compare Crohn's disease patients' assessment of disease activity and its effect on their well-being to their physician's assessment of the disease activity and the patient's well-being; and to use existing Crohn's disease indices in comparing the severity of Crohn's disease across various indices. The indices included in this study were the National Cooperative Crohn's Disease Study index, the Harvey and Bradshaw Index, the Oxford Index, the Modified Organisation Mondiale de Gastroentérologie Index, the Cape Town Index, the Bristol Index, and the St Marks Index. The comparison of Crohn's disease patient self-evaluation and physician evaluation of the patient indicates a significant agreement between patient and physician assessment of disease activity $\left(\chi^{2} 41.68, \mathrm{P}=0.00001\right)$. Cohen's weighted kappa, a chance-corrected coefficient of agreement for nominal scales, was also used to evaluate the quality of agreement between physician and patient assessment of well-being. The weighted kappa $(0.2322, \mathrm{P}=0.0002)$ indicates a significant level of agreement.

Key Words: Crohn's disease activity indices, IBD registry

\section{Analyse des indices d'activité de la maladie de Crohn d'après un registre de patients de l'est de la Pennsylvanie}

La présente étude a pour objectif d'examiner l'activité de la maladie telle qu'elle est évaluée par le patient et par le médecin, et l'effet de ces évaluations sur son bien-être; puis, de recourir aux principaux indices d'activité de la maladie utilisés pour mesurer la gravité de la maladie de Crohn et comparer les résultats obtenus de part et d'autres. Ont été inclus: le CDAI (National Cooperative Crohn's Disease Study Index, le HBI (Harvey and Bradshaw Index), l'OXI (Oxford Index), l'indice modifié de l'Organisation mondiale de gastroentérologie (OMGE), le CTI (Cape Town Index), le BRI (Bristol Index) et le SMI (St Marks Index). Il y a une correspondance significative entre l'évaluation que le patient et son médecin font de la maladie $\left(\chi^{2}=41,68, P=0,00001\right)$. L'indice Kappa pondéré (de Cohen), coefficient d'agrément utilisé pour les échelles nominales et permettant de corriger les différences fortuites, a également servi à évaluer le degré d'accord entre l'évaluation du patient et du médecin. Le kappa pondéré $(0,2322, \mathrm{P}=0,0002)$ confirme que les résultats sont significatifs.

The Allentown Hospital - Lehigh Valley Hospital Center, Allentown, Pennsylvania, USA Correspondence and reprints: Dr JF Reed, The Allentown Hospital - Lehigh Valley Hospital Center, 1200 South Cedar Crest Boulevard, Allentown, PA 18105, USA

Received for publication July 8, 1991. Accepted October 14, 1991
$\mathrm{T}$ HE DEVELOPMENT OF A RELIABLE and objective means of measuring disease 'activity' in Crohn's disease in terms of patient well-being has spanned several decades and has resulted in several indices (Tables 1-7) (1-9). These indices have been used to assess the activity of Crohn's disease and the response of the disease to a treatment regimen.

This report is neither a comprehensive review of these indices, nor is it a critique of those indices. For a review or critique of the disease activity indices, the authors defer to the papers by Bartholomeusz and Shearman (10), DeDombal (11), or Garrett and Drossman (12).

A major objective of the preliminary study to the National Cooperative Crohn's Disease Study (1) was to develop an index of the overall activity of Crohn's disease that would: incorporate factors considered to be important indicators of disease activity; use observations readily available during a patient visit; weigh the component factors in an intuitively appropriate direction; require only relatively simple computations; be consistent with the physician's overall appraisal of changes in the patient's condition; correlate well with the physician's overall appraisal of disease activity; and weigh the component factors to optimize accuracy with the predicted physicians' appraisal (1).

Eighteen independent variables were included. Each variable was coded in such a way that the normal value was 
TABLE 1

National Cooperative Crohn's Disease Study index of Crohn's disease activity $(1,2)$

No liquid or soft stools (each day for seven days)

Abdominal pain ( $0=$ None: $3=$ Severe)

General well-being ( $\mathrm{O}=\mathrm{Well} ; 4=$ Terrible)

Number of complications *

Taking Lomotil/opiates for diarrhea*

( $1=$ Yes: $0=$ No)

Abdominal mass* $(0=$ None:

$2=$ Questionable: $5=$ Definite)

Hematocrit* of 47 (males) or 42

(females)

Percentage deviation from standard

weight* (+ or - )

Seven consecutive day self-assessment on three variables. "Collected by proband interview and physician contact. Lomotil is diphenoxylate hydrochloride (Searle)

\section{TABLE 2}

Harvey and Bradshaw Index of Crohn's disease activity (3)

General well-being ( $\mathrm{O}=$ Well; $4=$ Terrible $)$

Abdominal pain ( $0=$ None: $3=$ Severe)

Number of liquid stools daily

Abdominal mass $(0=$ None:

2=Questionable: $5=$ Definite)

Complications

One day scoring

0 , and progressively larger values were expected to reflect greater activity of Crohn's disease. The dependent variable for each patient was the physician's overall evaluation of 'how the patient was doing'. Four categories were established: 'very well', 'fair to good', 'poor', and 'very poor'. A stepwise multiple regression model identified eight significant variables as contributors to the Crohn's disease activity index (CDAI) (1). CDAI values of 150 or below are associated with quiescent disease (physician evaluation of 'very well' or 'fair to good'). CDAI values above 150 are associated with active disease (physician evaluation of 'poor' or 'very poor'). The CDAI has served as the hallmark in the development of subsequent Crohn's disease indices (2-9). The authors also use this index as the basis of the present report.

The objectives of this report were: to compare Crohn's disease patients' assessments of disease activity, with respect to active and quiescent disease, to their physicians' assessments of disease activity; and to use the existing
TABLE 3

Oxford Index of Crohn's disease activity (2)

Pain

Bowels open 6+ per day or blood and

mucus in stools

Perianal complications

Fistula

Other complications

Mass present

Wasting or emaciated

Temperature above $38^{\circ} \mathrm{C}$

Tenderness

Hemoglobin less than $10 \mathrm{~g} / \mathrm{dL}$

Scoring + or - (present or absent)

Crohn's disease indices in comparing the severity of Crohn's disease across the various disease activity indices.

\section{MATERIALS AND METHODS}

An inflammatory bowel disease registry was established in 1987 in the Lehigh Valley in eastern Pennsylvania. The Lehigh Valley is located approximately $144 \mathrm{~km}$ west of New York City and $96 \mathrm{~km}$ north of Philadelphia. The area has a stable population of approximately one million. Ninety-five per cent of the population are white, and a majority are descendants of 'Pennsylvania Dutch' Protestants. This registry has 359 index probands (patients) which were referred to the registry office by diagnosing physicians. After obtaining consent from the patient, a basic history questionnaire was administered by trained registry staff. This questionnaire seeks information regarding the date of onset of symptoms, family history status, medication history, and lifestyle factors prior to the onset of symptoms and Crohn's disease diagnosis.

The Crohn's disease indices included in this study were the National Cooperative Crohn's Disease Study index (CDAI) (Table 1) (1,2), the Harvey and Bradshaw Index (HBI) (Table 2) (3), the Oxford Index (OXI) (Table 3) (2), the OMGE Index (Modified Organisation Mondiale de Gastroentérologie Research Committee) (Table 4) (4), the Cape Town Index (CTI) (Table 5) (4,5), the Bristol Index (BRI) (Table 6) (8), and the St Marks Index (SMI) (Table 7) $(6,7)$.

Information letters were mailed to
TABLE 4

OMGE (Modified Organisation Mondiale de Gastroentérologie Research Committee) index of Crohn's disease activity (4)

General well-being $(0=$ Very well: 1=Slightly below par; $2=$ Poor: $3=$ Very poor; $4=$ Terrible)

Abdominal pain $(0=$ None: $1=$ MIld: 2=Moderate; $3=$ Severe)

Bowel action ( $0=$ Normal; $5=10+$ bowel motions per day)

Complications (1=Pain in joints; 1=Eye inflammation; $1=$ Acute inflammatory skin disease: 1=Rapid evolving skin ulcer: $1=$ Small ulcers in the mouth; $1=$ Anal fissure: $1=$ New fistula: $1=$ Abscess: $1=$ Fever over $37.8^{\circ} \mathrm{C}$ )

physicians on September 7, 1990. The purposes of the letter were to inform the physician of initiation of the project and of an intention to contact their patients, and to ask for their support in completing the physician assessment of their patient's disease.

Each registry patient was then sent a letter that explained the study and included a CDAI diary, instructions for completing the diary, and a pre-addressed, postage-paid envelope. The patient diary was used to collect data over a one week period for computation of the CDAI (Table 8).

A review of the Crohn's disease index components enabled the authors to design and test a composite interview/ data collection instrument. This form was used for patient interviews and facilitated computation of the various indices (Table 9). Patient telephone interviews began on September 10, 1990 and were completed on October 9, 1990.

After the patient had been interviewed, a three part questionnaire was mailed to the patient's physician (Table 10). Part 1 of this questionnaire was the physician's assessment of the patient's status related to the disease. The CDAI assessment categories of 'very well', 'fair to poor', 'poor' and 'very poor' were used. Part 2 was the physician confirmation of the inflammatory bowel disease diagnosis and the procedure used in making the diagnosis (pathological, endoscopic, radiological, or clinical). Part 3 was data relating to the patient's 


\section{TABLE 5}

Cape Town Index of Crohn's disease activity $(4,5)$

Diarnea

Abdominal pain

Well-being

Complications:

Local (skin tag, sinus, fistula)

Systemic

Temperature

Percentage weight gained/lost from

last assessment

Abdominal mass

Abdominal tenderness

Hemoglobin

\section{TABLE 6}

Bristol Index of Crohn's disease activity (8)

Sense of well-being

Abdominal pain

Bowel frequency

Rectal bleeding

Recent weight loss

Pyrexia

Abdominal mass (+ or - )

Abdominal tenderness

Anal lesion

Enterocutaneous fistula

Joint, ey or mucocutaneous lesions

Scoring: $0=$ Absent: $1=$ Mild with no limitation of activity; $2=$ Moderate with some limitation of activity; $3=$ Severe with considerable limitation of activity

\section{TABLE 7}

St Marks Index of Crohn's disease activity $(6,7)$

\section{Clinical $^{\circ}$}

Sense of well-being

Abdominal pain

Bowel frequency

Rectal bleeding

Recent weight loss

Pyrexia

Abdominal mass (+ or - )

Abdominal tenderness

Anal lesion

Enterocutaneous fistula

Joint, eye or mucocutaneous lesions Laboratory ${ }^{\dagger}$

Hemoglobin

White blood cell count

Eythrocyte sedimentation rate

Albumin

Scoring: $0=$ Absent: $1=$ Mild with no limitation of activity: $2=$ Moderate with some limitation of activity: $3=$ Severe with considerable limitation of activities. 'Scoring: 0 to 2 (total possible laboratory score is 8 )
TABLE 8

Seven day daily patient diary for disease activity index data form (Fall 1990)

\begin{tabular}{|c|c|c|c|c|c|c|c|}
\hline Day & 1 & 2 & 3 & 4 & 5 & 6 & 7 \\
\hline $\begin{array}{l}\text { Number of liquid or very } \\
\text { stools }\end{array}$ & & & & & & & \\
\hline $\begin{array}{l}\text { Abdominal pain } \\
\qquad \begin{aligned} 0 & =\text { None } \\
1 & =\text { Mild } \\
2 & =\text { Moderate } \\
3 & =\text { Severe }\end{aligned}\end{array}$ & & & & & & & \\
\hline $\begin{array}{l}\text { General well-being } \\
\qquad \begin{aligned} 0 & =\text { Generally well } \\
1 & =\text { Slightly under par } \\
2 & =\text { Poor } \\
3 & =\text { Very poor } \\
4 & =\text { Terrible }\end{aligned}\end{array}$ & & & & & & & \\
\hline
\end{tabular}

TABLE 9

Inflammatory Bowel Disease (IBD) Registry survey - Form A: Crohn's disease activity indices survey (Fall 1990)

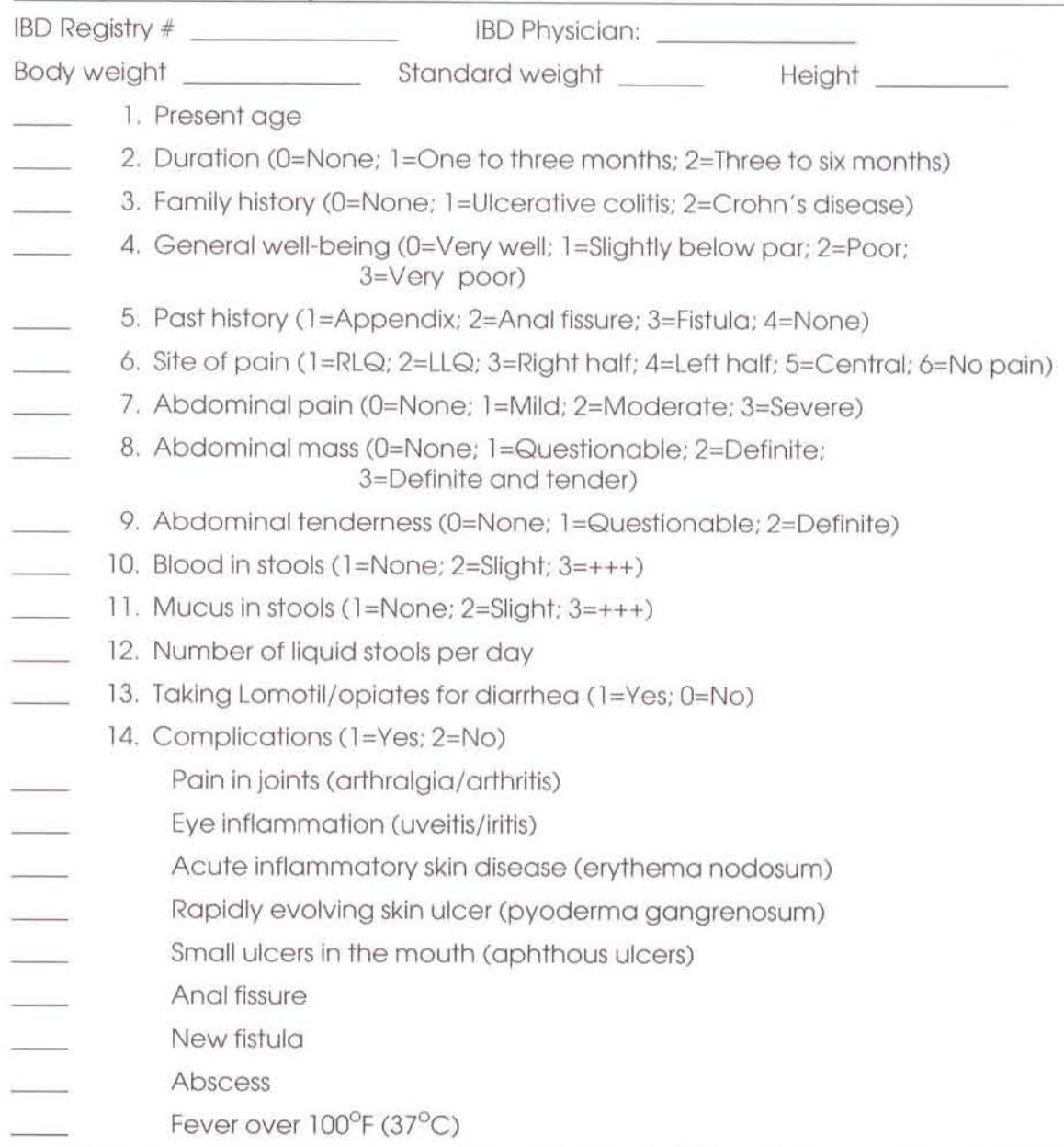

LQ Left lower quadrant; RLQ Right lower quadrant. Lomotil is diphenoxylate hydrochloride (Searle) 
most recent laboratory results (white blood cell count, erythrocyte sedimentation rate, albumin, hemoglobin, hematocrit and platelets). The data were obtained from the record of the patient's last visit.

Cohen's weighted kappa $\left(\kappa_{w}\right)$, a chance-corrected coefficient of agreement for nominal scales, was used to evaluate the quality of agreement between the physician and patient assessments of well-being. The $\kappa_{w}$ coefficient adjusts for the differential seriousness of misclassification errors.

Pearson product moment correlation analysis was used to measure the relationship between the physician assessment of well-being and the Crohn's disease index of disease severity. Because of the large number of statistical tests being performed, the usual alpha (0.05), was adjusted to 0.025 (Bonferroni adjustment) to reduce the probability of detecting spurious correlations.

In many situations it is useful to have

TABLE 11

Comparison of physician and patient evaluations of Crohn's disease patients in an inflammatory bowel disease registry in eastern Pennsylvania

\begin{tabular}{lccc}
\hline & \multicolumn{3}{c}{ Physician evaluation } \\
Patient & Very & Fair/ & \\
evaluation & well & good & Poor \\
\hline Very well & 76 & 26 & 2 \\
Fair/good & 29 & 25 & 1 \\
Poor & 2 & 3 & 3 \\
Very poor & 0 & 3 & 1 \\
\hline
\end{tabular}

Weighted kappa 0.2322, $P=0.0002$

TABLE 10

Inflammatory Bowel Disease (IBD) Registry survey - Form B: Crohn's disease activity indices physician survey (Fall 1990)

Patient's name

IBD Registry \#

Part 1. Physician evaluation of patient

General well-being ( $1=$ Very well; $2=$ Fair to good: 3=Poor; $4=$ Very poor)

Part 2. Confirmation of diagnosis

$$
\begin{aligned}
\text { Diagnosis } & \text { Crohn's disease } \\
\text { Procedure } & \text { Ulcerative colitis } \\
& \text { Pathological } \\
& - \text { Endoscopic } \\
& \\
&
\end{aligned}
$$

Part 3. Laboratory results

$\begin{array}{lll}\text { White blood cell count } & \quad & \text { Erythrocyte sedimentation rate } \\ \text { Albumin } & \quad \text { Hemoglobin } \\ \text { Hematocrit } & \quad \text { Platelets }\end{array}$

Notes:

summary displays of the data (distribution). One simple method is the box plot. In the box plot, the upper and lower quartiles of the data are portrayed by the top and bottom of a rectangle, and the median is portrayed by a

TABLE 12

Crohn's disease index correlations

\begin{tabular}{lccccccc}
\hline & CDAI & HBI & OXI & OMGE & CTI & SMI & BRI \\
\hline HBI & 0.447 & & & & & & \\
OXI & 0.466 & 0.708 & & & & & \\
OMGE & 0.473 & 0.950 & 0.815 & & & & \\
CTI & 0.452 & 0.821 & 0.686 & 0.866 & & & \\
SMI & 0.520 & 0.747 & 0.897 & 0.849 & 0.902 & & \\
BRI & 0.439 & 0.766 & 0.887 & 0.841 & 0.897 & 0.981 & \\
Clinical & 0.329 & 0.473 & 0.371 & 0.568 & 0.347 & 0.428 & 0.348 \\
\hline
\end{tabular}

BRI Bristol Index (8): CDAINational Cooperative Crohn's Disease Study (1.2); Clinical Physician clinical judgement of disease activity: CTI Cape Town Index (4.5): HBI Harvey and Bradshaw Index (3); OMGE Modified Organisation Mondiale de Gastroentérologie Research Committee (4); OXI Oxford Index (2): SMI St Marks Index (6,7)
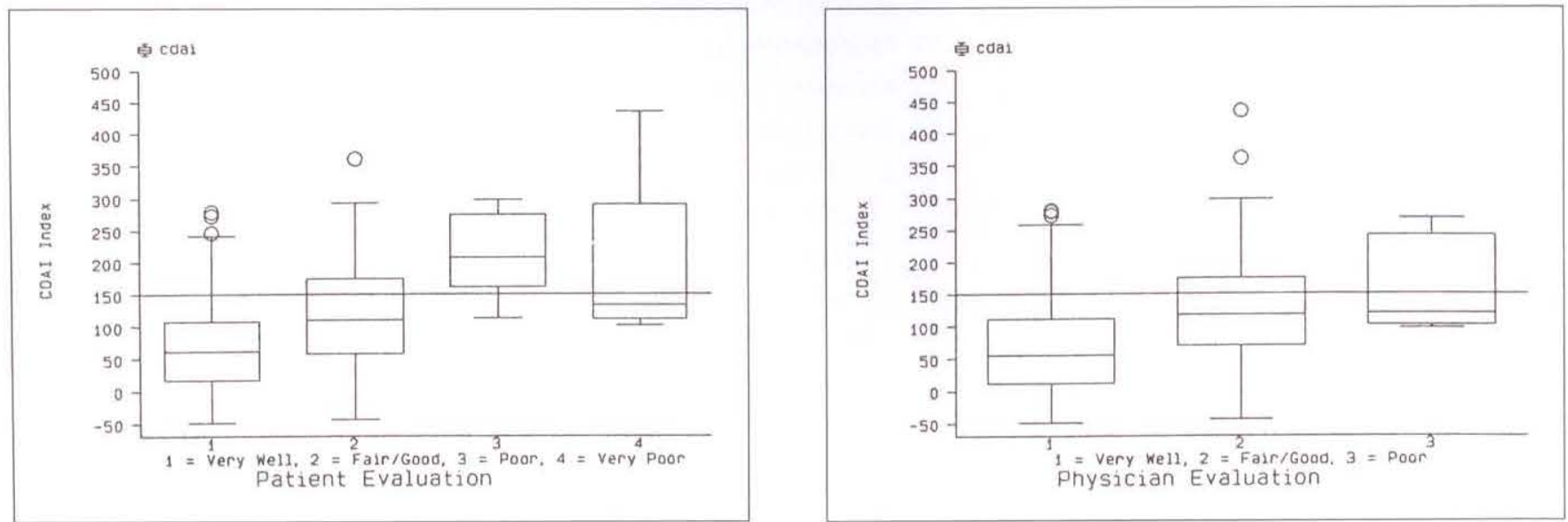

Figure 1) National Cooperative Crohn's Disease Study index (CDAI) $(1,2)$ results in patients taken from an inflammatory bowel disease registry in eastern Pennsylvania. Patient and physician evaluations of disease activity 

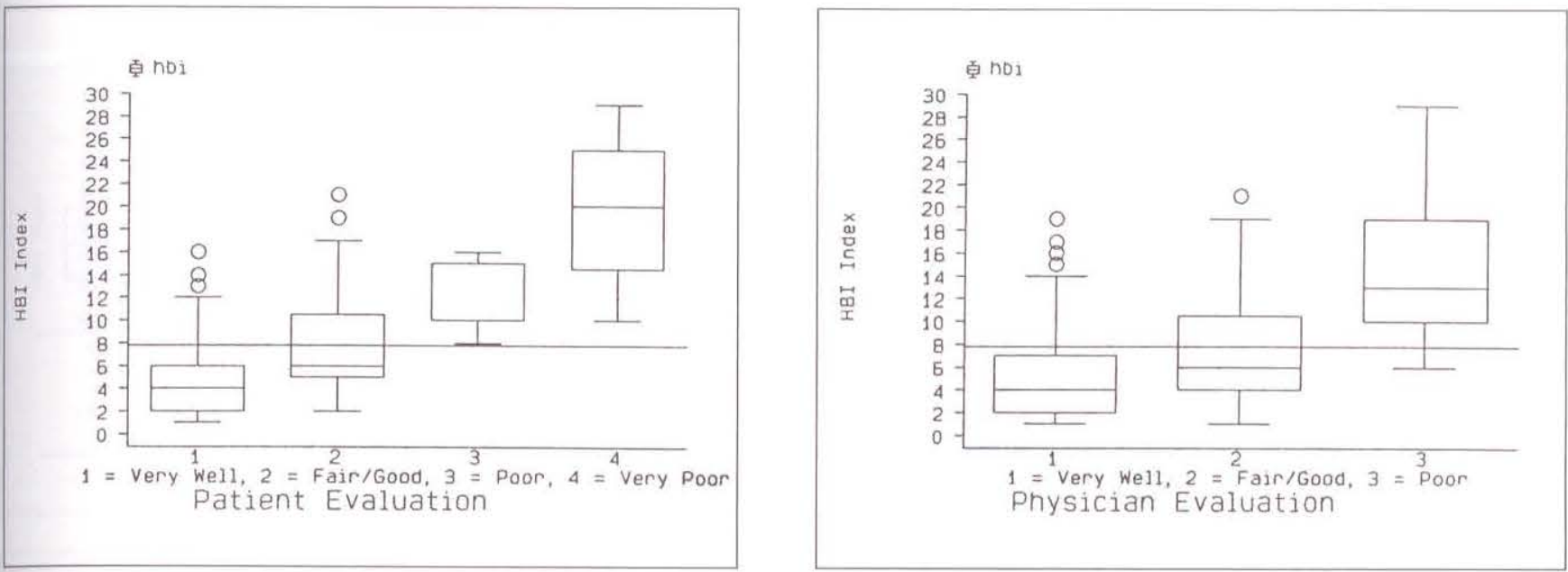

Figure 2) Harvey and Bradshaw Index (HBI) (3) results in Crohn's disease patients taken from an inflammatory bowel disease registry in eastern Pennsylvania. Patient and physician evaluations of disease activity
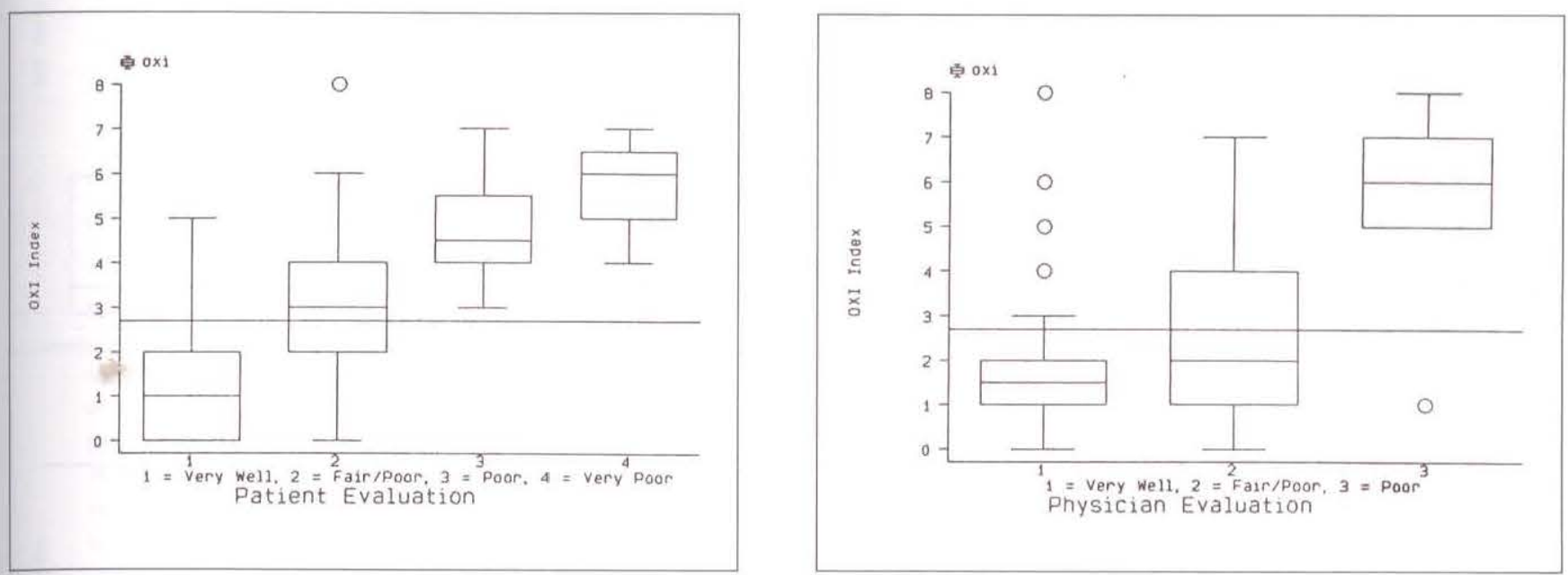

Figure 3) Oxford Index (OXI) (2) results in Crohn's disease patients taken from an inflammatory bowel disease registry in eastern Pennsylvania. Patient and physician evaluations of disease activity
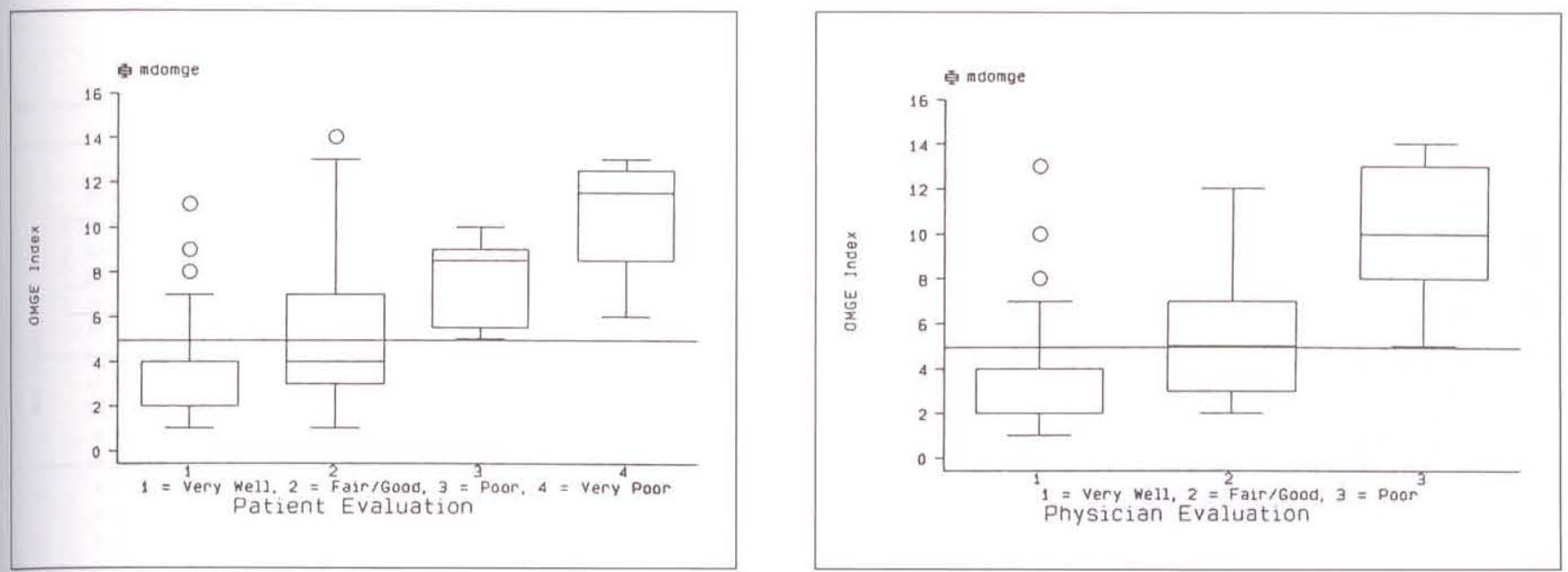

Figure 4) OMGE Index (Modified Organisation Mondiale de Gastroentérologie Research Committee) (4) results in Crohn's disease patients taken from an inflammatory bowel disease registry in eastern Pennsylvania. Patient and physician evaluations of disease activity 

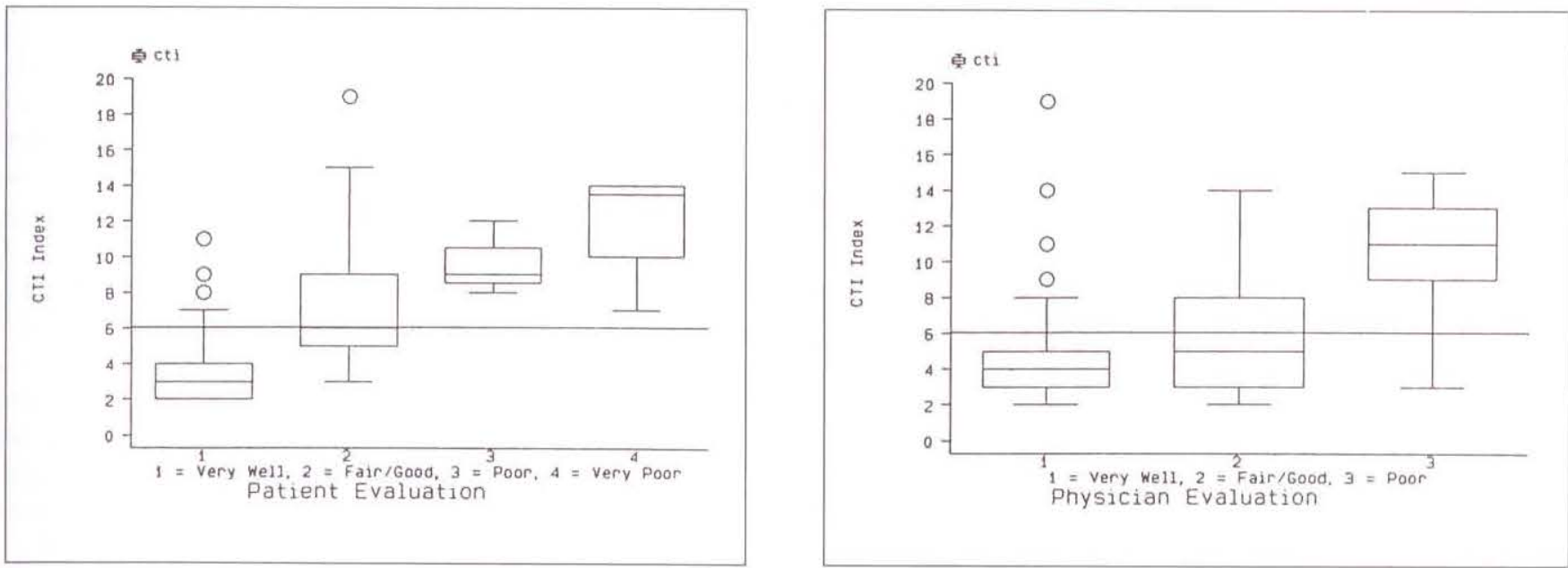

Figure 5) Cape Toun Index (CT1) (4,5) results in Crohn's disease patients taken from an inflammatory bowel disease registry in eastern Pennsylvania. Patient and physician evaluations of disease activity
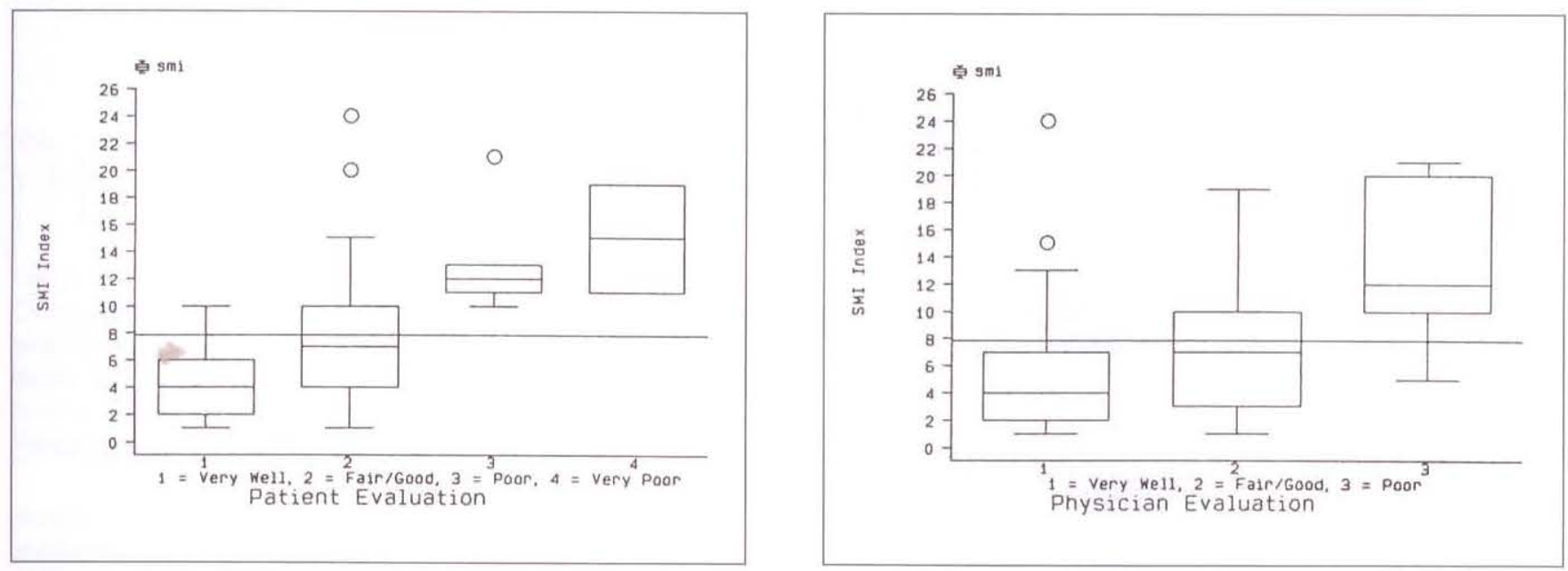

Figure 6) St Marks Index (SMI) (6,7) results in Crohn's disease patients taken from an inflammatory bowel disease registry in eastern Pennsylvania. Patient and physician evaluations of disease activity
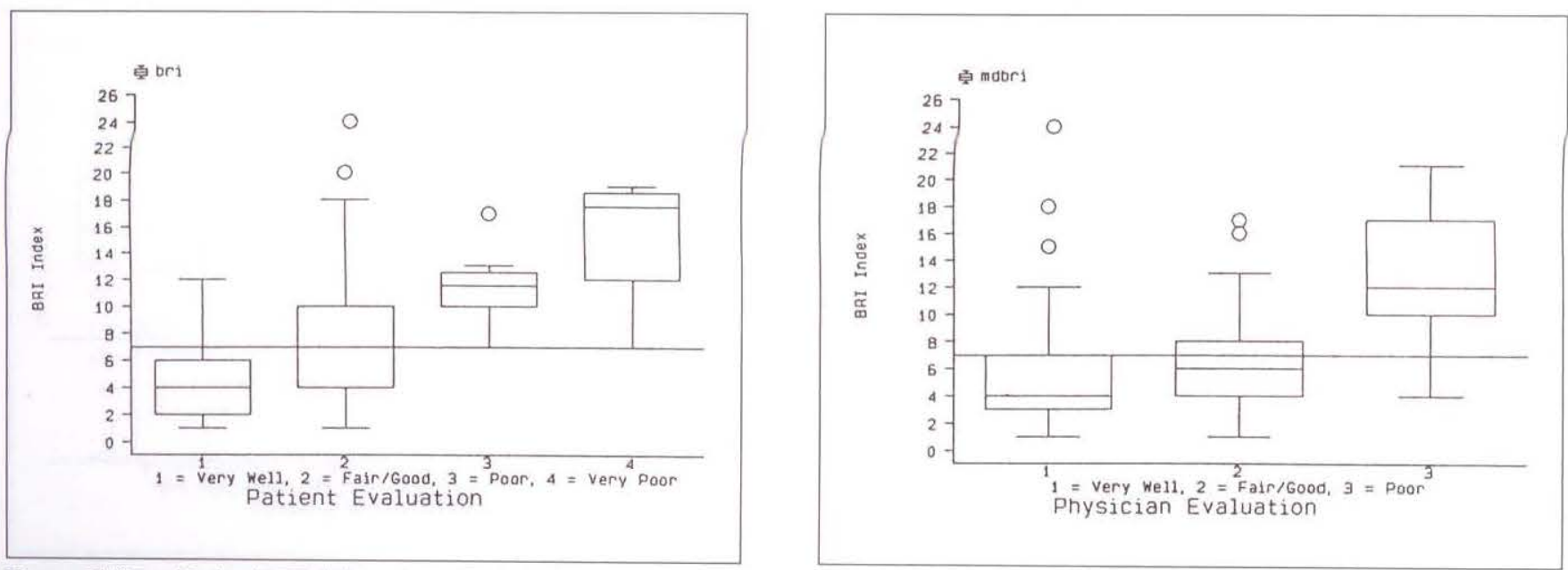

Figure 7) Bristol Index (BRI) (8) results in Crohn's disease patients taken from an inflammatory bowel disease registry in eastern Pennsylvania. Patient and physician evaluations of disease activity 

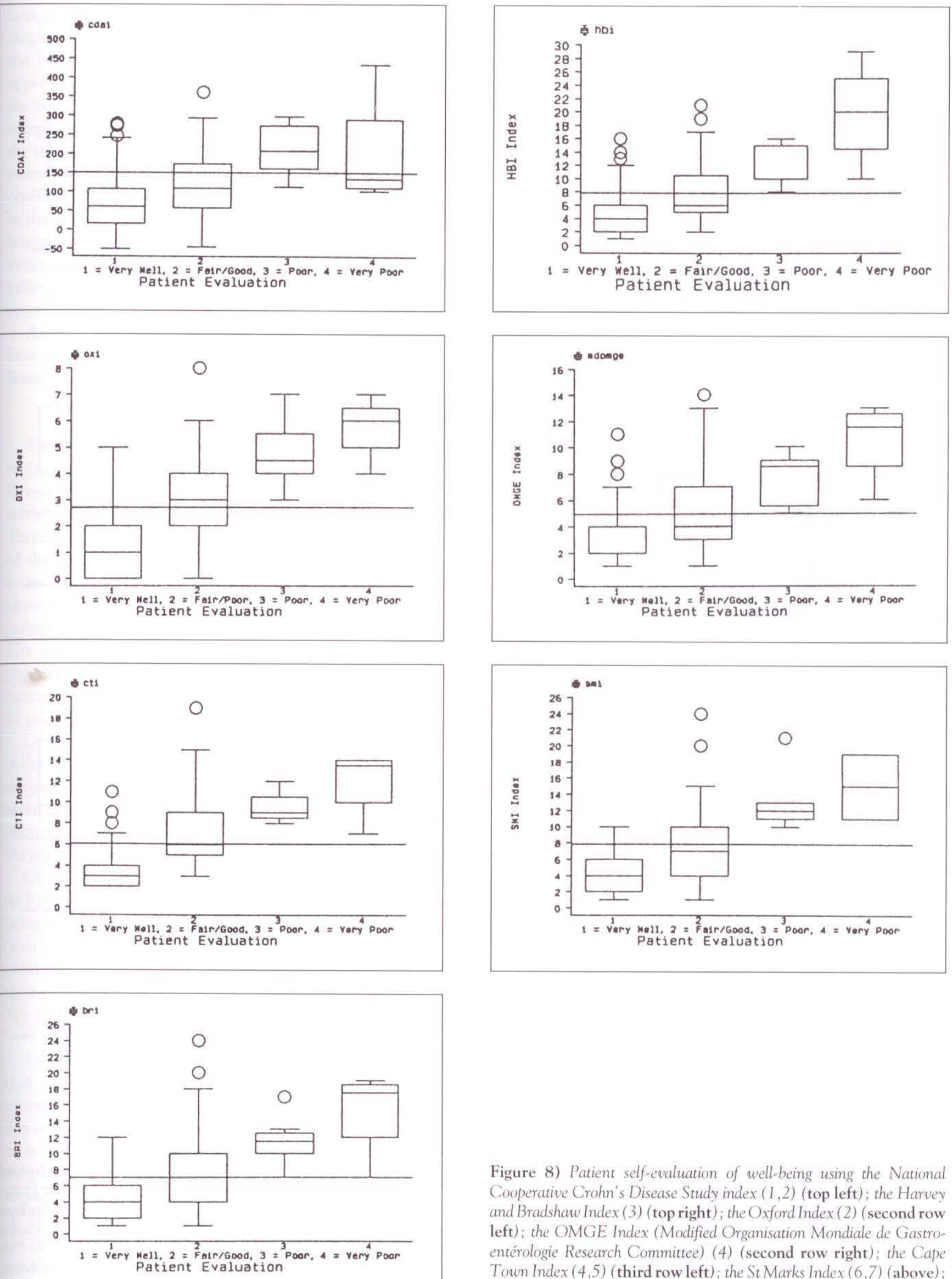

Figure 8) Patient self-evaluation of well-being using the National Cooperative Crohn's Disease Study index $(1,2)$ (top left); the Harvey and Bradshaw Index (3) (top right); the Oxford Index (2) (second row left); the OMGE Index (Modified Organisation Mondiale de Gastroentérologie Research Committee) (4) (second row right); the Cape Toun Index (4,5) (third row left); the St Marks Index (6,7) (above); and the Bristol Index (8) (bottom left) 

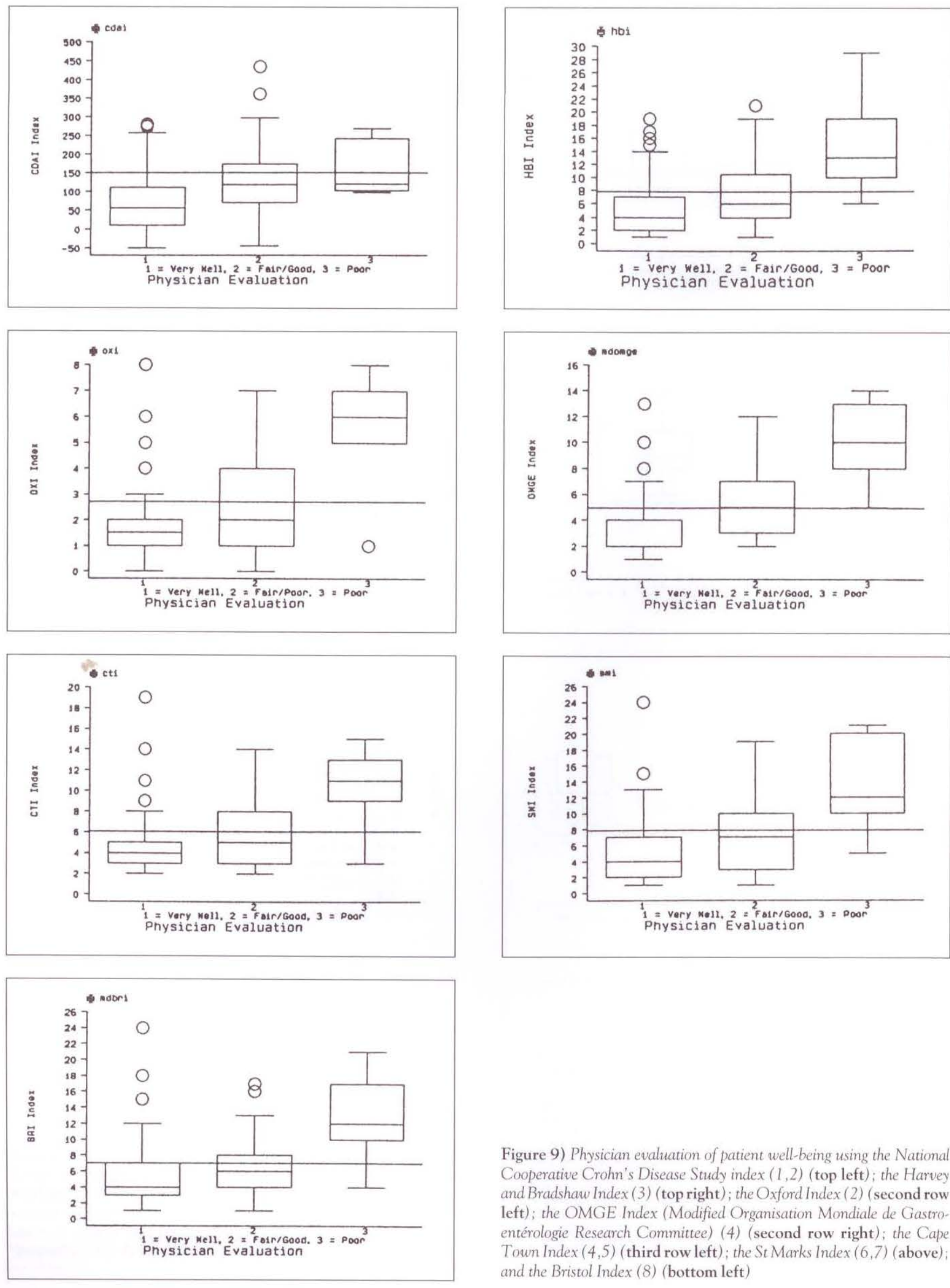

Figure 9) Physician evaluation of patient well-being using the National Cooperative Crohn's Disease Study index $(1,2)$ (top left); the Harvey and Bradshaw Index (3) (top right); the Oxford Index (2) (second row left); the OMGE Index (Modified Organisation Mondiale de Gastroentérologie Research Committee) (4) (second row right); the Cape Town Index (4,5) (third row left); the St Marks Index (6,7) (above); and the Bristol Index (8) (bottom left) 
horizontal line segment within the rectangle. Lines extend from the ends of the box to the adjacent values. The upper 'adjacent values' is defined to be the largest observation that is less than or equal to the upper quartile plus 1.5 of the interquartile range. The lower adjacent value is defined to be the smallest observation that is greater than or equal to the lower quartile minus 1.5 of the interquartile range. If any of the observations fall outside of the two adjacent values, it is plotted as an individual point. Extreme values are plotted as Es.

Analysis was limited to Crohn's disease patients in the Inflammatory Bowel Disease Registry.

\section{RESULTS}

Three hundred and twenty patients of the 359 in the Inflammatory Bowel Disease Registry were contacted and interviewed by one of the authors (LAF). Three hundred and seventeen completed the interview, and 219 returned a seven day diary (CDAI). Seventy-two physicians were represented by the 317 patients. The physicians then returned 276 three part questionnaires. The physician population consisted of 37 internists, 28 gastroenterologists, and 12 colorectal surgeons.

Of the 218 Crohn's disease patients in the registry, $171(78.4 \%)$ completed the patient interview, 120 returned the seven day diary, and 171 corresponding physician assessments were returned to the authors' office.

Of the 171 patient assessments of well-being, 104 reported themselves as being 'very well', 55 'fair to good', eight 'poor', and four 'very poor'. Of 171 physician assessments, 108 reported their patients as being 'very well', 56 'fair to good', seven 'poor', and none 'very poor'.

Table 11 displays the cross-tabulation results of the Crohn's disease patient evaluation by physician evaluation of the patient. A $\chi^{2}$ analysis indicates significant agreement between the patient and physician assessments between active and quiescent disease $\left(\chi^{2} 41.68, P=0.00001\right)$. The strength of the agreement $\left(\kappa_{W} 0.2322, P=0.0002\right)$ was also significant.

Table 12 details a complete correla- tion matrix between the Crohn's disease index and physician's clinical judgement. The correlations range from the low CTl and clinical $(r=0.347)$ to the highest correlation between the BRI and SMI ( $r=0.981)$. The BRI and SMI were expected to be nearly identical. The only difference between these two indices is the inclusion of laboratory values (hemoglobin, white cell blood count, erythrocyte sedimentation rate, and albumin) in the SMI.

The box plots are displayed for the CDAI in Figure 1. A CDAI score of less than or equal to 150 was identified as the cutoff point between active and quiescent disease (1). The median of the 'very well' and 'fair to good' categories for both physician and patient evaluations fell below the 150 score cutoff point.

Figure 2 displays the box plots for the $\mathrm{HBI}$. An HBI score of less than or equal to 7.8 was identified as the cutoff point corresponding to the CDAI cutoff point of 150 between active and quiescent disease. The median for the 'very well' and 'fair to good' categories for both physician and patient evaluations fell on or below the 7.8 cutoff point. In the 'poor' and 'very poor' categories, the median plots are above the 7.8 cutoff point.

The OXI plots are given in Figure 3. An OXI score of 2.7 corresponds to the CDAI cutoff point of 150 . Physician evaluation of disease state for patients in the 'very well' and 'fair to good' categories are below the 2.7 cutoff point. Patient evaluation in the 'fair to good' category is slightly above the cutoff point.

The OMGE and CTI (Figures 4,5) performed as expected, with the 'very well' and 'fair to good' box plot categories at or below the OMGE 4.94 cutoff point and the CTI 6.06 cutoff point.

The SMI and BRI indices are nearly identical (Figures 6,7). The cutoff points corresponding to that of the CDAI (150) are 7.87 and 7.00 , respectively. The box plots were as expected.

In Figures 8 and 9, the consistency of the various Crohn's disease indices in relation to patient or physician evaluation is graphically illustrated by the box plots.

\section{DISCUSSION}

Myren et al (4) reported higher correlations between clinical opinion and OMGE (0.771), clinical opinion and OXI (0.557), and OMGE and OXI $(0.756)$, than were found in the present study. The differences between the correlations are likely due to the large number of physicians involved in the present study and the known interobserver variability within physician assessment of patient well-being, abdominal pain and abdominal mass. Another factor which could contribute to the lower correlations is the variability in health status of patients with inflammatory bowel disease.

One conclusion from the present study is clear. With any of the indices or when patient status is evaluated by patient or physician, a consistent pattern between active and quiescent disease is evident.

The question of which Crohn's disease index is more reliable has not been answered. However, given a point in time either from the patient's or physician's perspective, consistent measures of disease activity are available.

ACKNOWLEDGEMENTS: This study was supported by a grant from the Dorothy Rider Pool Health Care Trust.

\section{REFERENCES}

1. Best WR, Becktel JM, Singleton JW, Kern K Jr. Development of a Crohn's disease activity index: National Cooperative Crohn's Disease Study. Gastroenterology 1976;70:439-44.

2. Hodgson HJF. Assessment of drug therapy in inflammatory bowel disease. $\mathrm{Br} J$ Clin Pharmacol 1982;14:159-70.

3. Harvey RF, Bradshaw JM. A simple index of Crohn's disease activity. Lancet 1980;i:514.

4. Myren J, Bouchier IAD, Watkinson G, Softley A, Clamp SE, DeDombal FT. The OMGE multinational inflammatory bowel disease survey 1976-1982. A further report on 2657 cases. Scand J Gastroenterol 1984;19(Suppl 95):1-27.

5. Wright JP, Marks IN, Parfitt A. A simple clinical index of Crohn's disease activity - The Cape Town index. South Afr Med ] 1985;68:502-3.

6. Burnham WR, Lennard-Jones JE, Hecketsweiler P, Colin R, Geffroy Y. 
Oral BCG vaccine in Crohn's disease. Gut 1979;20:229-33.

7. Willoughby JMT, Kumar PJ, Beckett J, Dawson AM. Controlled trial of azathioprine in Crohn's disease. Lancet 1971;ii:944-7.

8. O'Donoghue DP, Dawson AM, Powell Tuck J, Bown RL, Lennard-Jones JE. Double blind withdrawal trial of azathioprine as maintenance treatment for Crohn's disease. Lancet 1978;ii:955-7.

9. Elliot PR, Lennard-Jones JE, Hathway N. Simple index of Crohn's disease. Lancet 1980; i:876.

10. Bartholomeusz FDL, Shearman DJC. Measurement of activity in Crohn's disease. J Gastroenterol Hepatol
1989;4:81-94.

11. DeDombal FT. Measures of disease activity. In: Bayless TM, ed. Current Management of Inflammatory Bowel Disease. Philadelphia: Decker Inc, 1989.

12. Garrett JW, Drossman DA. Health status in inflammatory bowel disease. Gastroenterology 1990;99:90-6. 


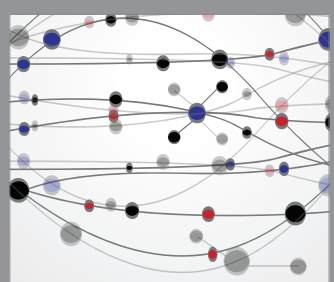

The Scientific World Journal
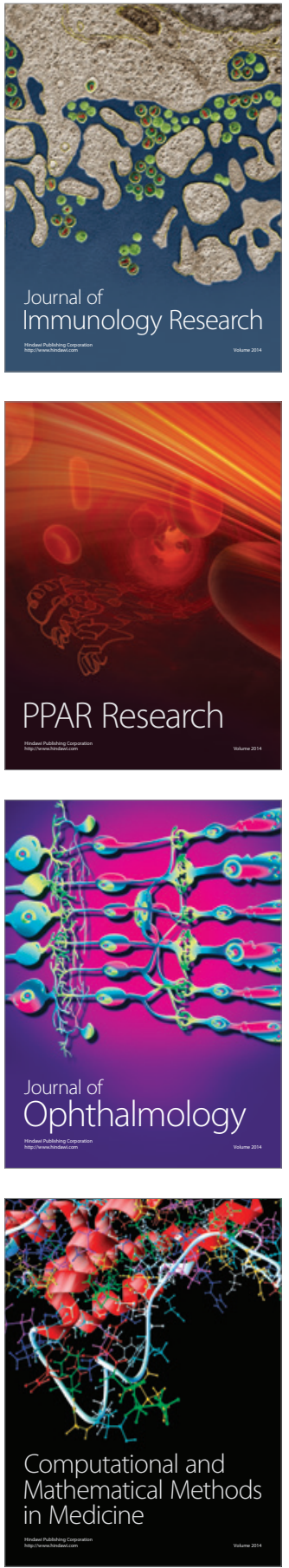

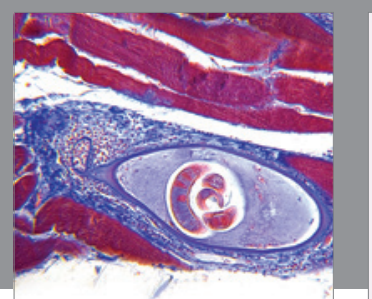

Gastroenterology Research and Practice

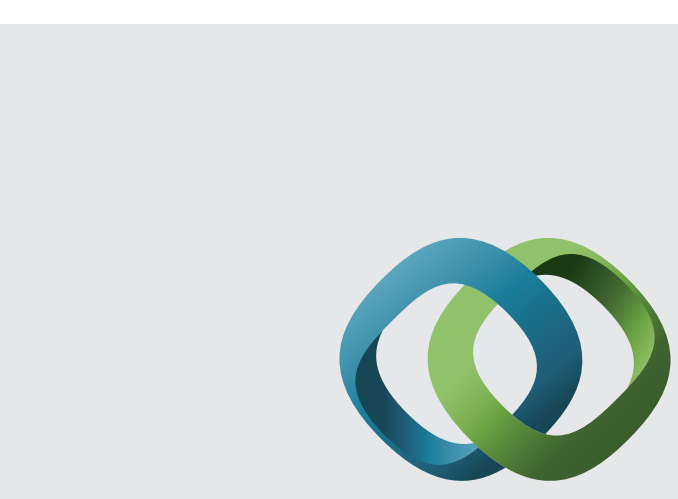

\section{Hindawi}

Submit your manuscripts at

http://www.hindawi.com
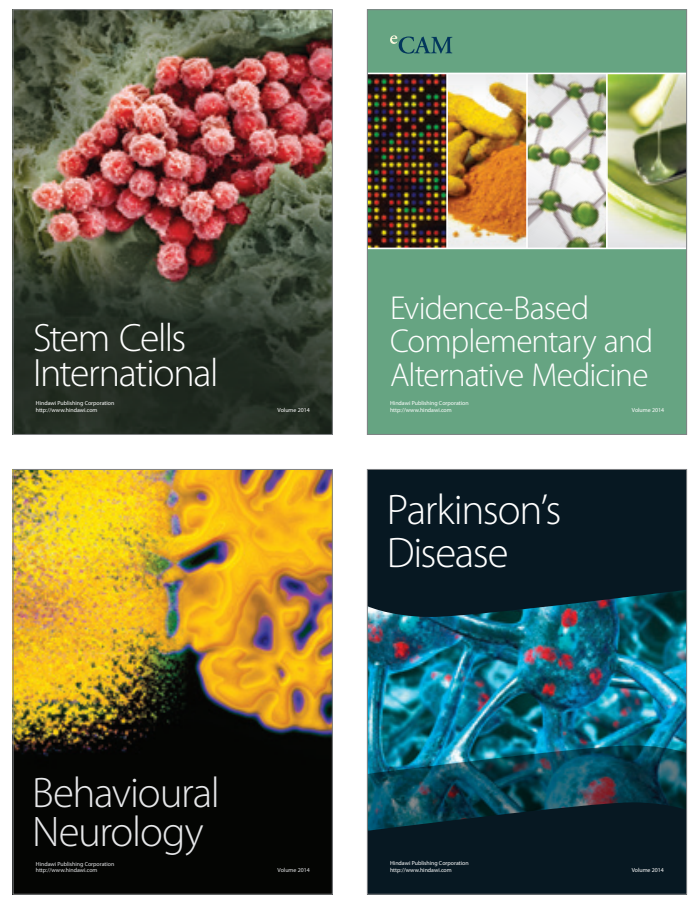
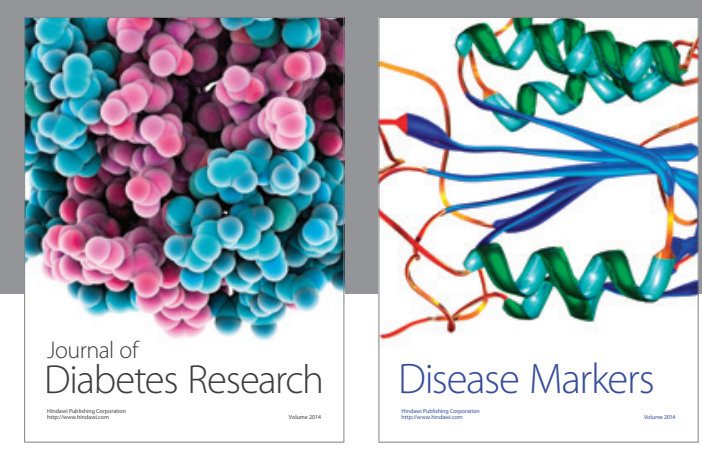

Disease Markers
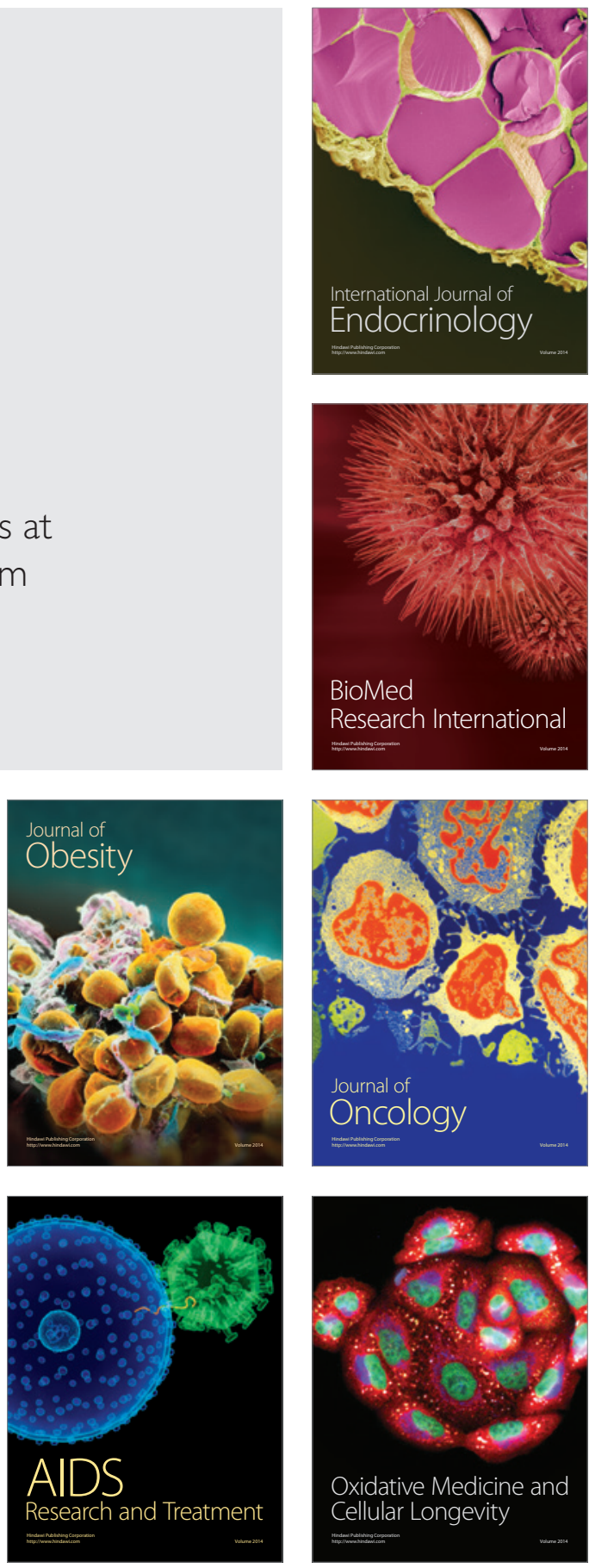